\title{
POSSIBLE ADVERSE EVENTS DURING IBD TREATMENT
}

\author{
Adriana Krasteva*, Assya Krasteva**, Angelina Kisselova** \\ *Department of Pharmacology and Toxicology, Faculty of Pharmacy, Medical \\ University - Sofia \\ **Department of Oral Imaging and Oral Diagnostic, Faculty of Dental Medicine, \\ Medical University - Sofia
}

\begin{abstract}
Inflammatory bowel diseases (IBD) refer to two chronic diseases which involve the large and small intestines: ulcerative colitis and Crohn's disease.

The aim of the review is to focus on main oral signs which are related to a specific treatment. Most of the articles on IBD patients consider just the typical oral disease manifestations, without taking into account oral manifestations as results from the administrated treatment.

Key words: Inflammatory bowel diseases, oral signs, treatment

\section{INTRODUCTION}

Inflammatory bowel disease refers to two chronic diseases that cause inflammation of the intestines: ulcerative colitis (UC) and Crohn's disease (CD). Although the diseases have some features in common, there are some important differences (8).

Ulcerative colitis is an inflammatory disease of the large intestine, or colon. In ulcerative colitis, the inner lining (mucosa) of the intestine becomes inflamed (red and swollen) and develops ulcers (open, painful wounds). Ulcerative colitis is often the most severe in the rectal area, which can cause frequent diarrhea. Mucus and blood often appear in the stool (feces or poop) if the lining of the colon is damaged $(4,8)$.

Crohn's disease differs from ulcerative colitis in the areas of the bowel it involves - it most commonly affects the last part of the small intestine (called the terminal ileum) and parts of the large intestine. However, it isn't limited to these areas and can attack any part of the digestive tract. Crohn's disease causes inflammation that extends much deeper into the layers of the intestinal wall and generally tends to involve the entire bowel wall, whereas ulcerative colitis affects only the lining of the bowel $(4,8)$.

Crohn's disease and ulcerative colitis present usually have some extra-intestinal oral and systemic manifestations (such as arthritis, skin and oral manifestations and eye problems $(4,8)$.
\end{abstract}

Oral symtoms related to IBD based on three important conditions:

1. Oral signs corresponding to the activity of the disease;

2. Oral manifestation which may precede the onset of intestinal lesions;

3. Oral findings which are related to a specific treatment - and we would like to accentuate on this negligee problem

In patients with IBD often can be observed nonspecific oral signs $(1,2,3,5,6)$, wgich usually hamper the diagnosis:

- candidiasis and angular cheilitis;

- chronic bleeding;

- chronic stomatitis;

- cobblestone appearance of the oral mucosa;

- gingival swelling;

- gingivitis and acute periodontitis (occurs more frequently and progress rapidly than in healthy patients);

- granulomatous inflammation of minor salivary ducts;

- increased risk of dental caries;

- lichenoid mucosal reaction;

- lymphadenomegaly

- orofacial granulomatosis;

- persistent lip swelling;

- pyostomatitis vegetans;

- recurrent aphthous ulcerations;

- xerostomia;

- erythema migrans;

Oral signs related to specific IBD treatment should be considered by dental practitioners.

Some of the oral findings could be a result of systemic medication (mainly glucocorticosteroids, sulfasalazine and immunosuppressants) and chronic use of topical corticosteroids (Table 1.) $(1,3,7)$. 
Table 1.

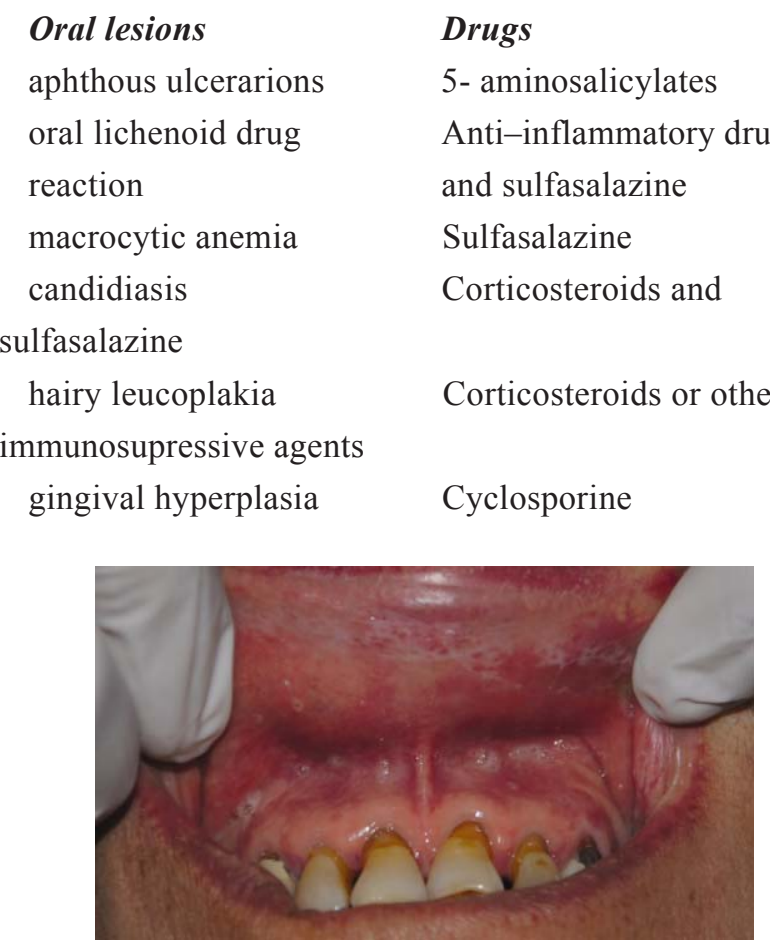

Fig. 1. Oral lichenoid drug reaction

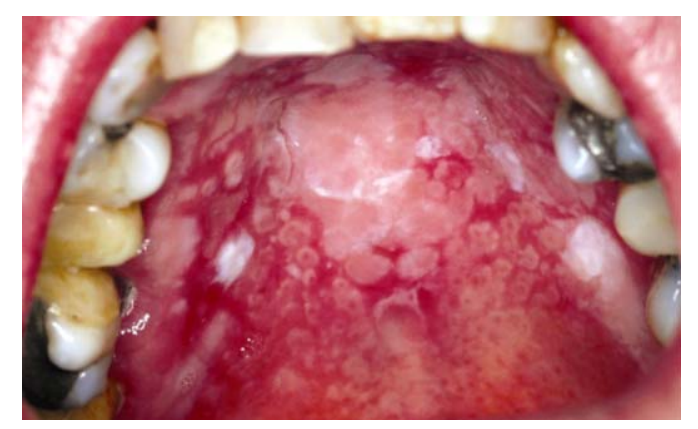

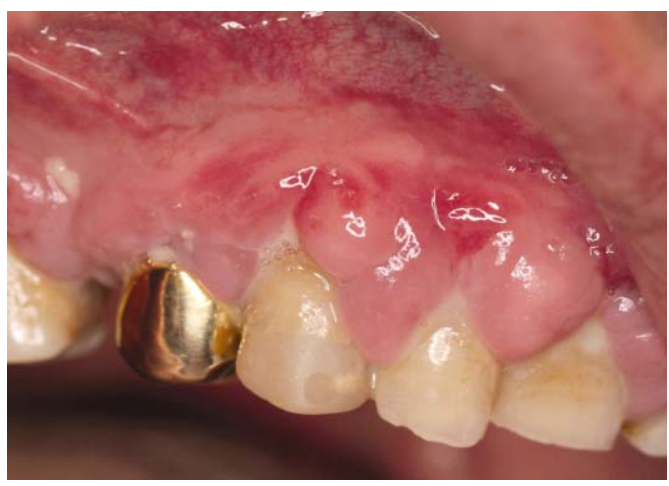

Fig. 3. Gingival hyperplasia

It is important to be noted that long-term treatment with some medication can induce serious adverse events as:

- Hypertension and hyperglycemia - due the corticosteroids and $\mathrm{ACTH}$

- Osteoporosis - due to prolonged intake of corticosteroids

- Adrenal suppression - due to longer treatment with corticosteroids

- Changes in white or red blood cell counts - due to azathioprine treatment $(1,3,7)$.

\section{CONCLUSION}

Oral lesions in patients with IBD could be a major problem and dental care can ameliorate not only the oral health but could also improve the general patient condition by correcting the door of the gastrointestinal system.

Fig. 2. Candidiasis

\section{REFERENCES:}

1. Basu M., Asquith P., Thompson A., Cooke W. (1975) Gut, 16, 249-254.

2. Bricker S., Langlais R., Miller C. (1994) In: Oral Diagnosis, oral medicine and treatment planning (Lea \& Febiger a Waverly company, Ed.), BC Decker Inc., Hamilton, Canada, 274-277.

3. Hanauer S. (2006) Inflamm. Bowel
Dis., 12, 3-9.

4. Krastev Z. and Kisselova A. (2009)

In: Oral medicine, I. Sapunjiev EOOD, Sofia, 354-358 (in Bulgarian).

5. Krasteva A., Kisselova A., Panov V1. Guirova B., Krasteva A., Bobeva A. (2011) Oral lesions, I. Sapunjiev EOOD, Sofia. (in Bulgarian)
6. Krasteva A. (2009) Dissertation.

7. Siegel M. (1989) In: Current therapy in gastroenterology and liver disease (T.M. Bayless, Ed.), Mosby-Year Book, St. Louis, 1-5.

8. Spassova Z. (2004) In: Internal Medicine, Tip-Top Press, Sofia, 241-246. (in Bulgarian)

\section{Address for correspondence:}

AssyaKrasteva

Department of Oral imaging and oral diagnostic, Faculty of Dental Medicine, Medical University - Sofia

1, Sveti Georgi Sofiiski Blvd., 1000 Sofia, Bulgaria

E-mail: asyakrasteva@gmail.com 